Title:

\title{
Kinetic Studies of Competitive Adsorption Processes Related to Automobile Catalytic Converters
}

\section{Submitted to:}

F. Zaera, U.C.-Riverside

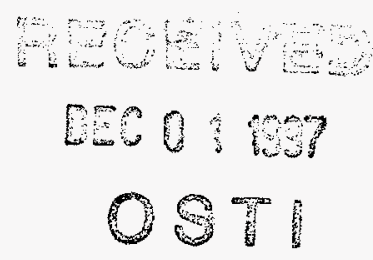

M. T. Paffett, CST-18

DOE Office of Scientific and Technical

Information (OSTI)

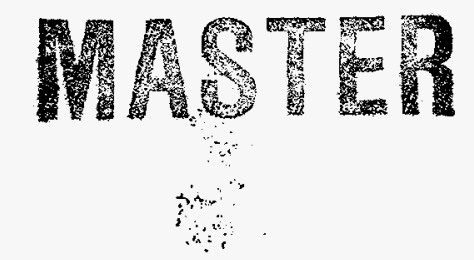

\section{Los Alamos}

NATIONAL LABORATORY

Los Alamos National Laboratory, an aftimative action/equal opportunity employer, is operated by the University of Calfomia for the U.S. Department of Energy under contract W-7405-ENG-36. By acceptance of this article, the publisher recognizes that the U.S. Government retains a nonexclusive, royallyfree ilcense to publish or reproduce the published form of this contribution, or to allow others to do so, for U.S. Government purposes. Los Alamos National Laboratory requests that the publisher identify this article as work performed under the auspices of the U.S. Department of Energy. Los Alamos National Laboratory strongly supports academic freedom and a researcher's right to publish; as an institution, however, the Laboratory does not endorse the viewpoint of a publication or guarantee its technical correctness. 


\section{DISCLAIMER}

This report was prepared as an account of work sponsored by an agency of the United States Government. Neither the United States Government nor any agency thereof, nor any of their employees, makes any warranty, express or implied, or assumes any legal liability or responsibility for the accuracy, completeness, or usefulness of any information, apparatus, product, or process disclosed, or represents that its use would not infringe privately owned rights. Reference herein to any specific commercial product, process, or service by trade name, trademark, manufacturer, or otherwise does not necessarily constitute or imply its endorsement, recommendation, or favoring by the United States Government or any agency thereof. The views and opinions of authors expressed herein do not necessarily state or reflect those of the United States Government or any agency thereof. 


\section{DISCLAMmER}

Portions of this docoment misy be illegible in electronic image prodnets. Images are produced from the best available origion docomentert. 


\title{
Kinetic Studies of Competitive Adsorption Processes Related to Automobile Catalytic Converters
}

\author{
Francisco Zaera* \\ Department of Chemistry, University of California-Riverside \\ Mark T. Paffett* \\ Chemical Science and Technology Division, Los Alamos National Laboratory
}

\begin{abstract}
This is the final report of a three-year, Laboratory Directed Research and Development (LDRD) project at Los Alamos National Laboratory (LANL). The goal of this project was to study the microscopic details for the adsorption of $\mathrm{CO}, \mathrm{NO}$, and $\mathrm{O}_{2}$ on transition metal surfaces under conditions resembling those present in automobile catalytic converters. Initial sticking coefficients were measured as a function of temperature on transition metal single crystals by using a method originally developed by King and Wells. These measurements were performed under conditions emulating those typical of competitive adsorption, namely, where the substrate is exposed to a mixture of two or more gases simultaneously, or where one molecule is adsorbed on the surface prior to exposure to the second gas. The experimental results were then analyzed by using a Monte Carlo computer simulation algorithm in an attempt to better understand the relevant aspects of the adsorption process.
\end{abstract}

\section{Background and Research Objectives}

Air pollution originating from internal combustion engine exhaust gases has become one of the most serious environmental problems in recent years. In response to the threat this problem poses to the quality of life in urban areas, many regions have advanced severe restrictions on the gas composition allowed for car emissions, and have required car manufacturers to improve catalytic conversion of exhaust gas emissions. The resulting catalytic converters have proven quite efficient in performing the two main requirements asked of them, namely, the oxidation of both carbon monoxide and unburned hydrocarbon molecules from gasoline, and the reduction of any nitrogen oxides produced during the

\footnotetext{
*Co-Principal Investigators, E-mail: francisco.zaera@ucr.edu and mtp@lanl.gov
} 
combustion processes. Unfortunately, in spite of this success, there are still serious problems associated with the long term stability of the materials used in these catalytic converters that need to be addressed. Furthermore, new, more stringent regulations will also require revision and improvement of the present formulations of active catalysts and supports.

The research project described here focused on an aspect of environmental chemistry related to the design of better automobile catalytic converters. The main goal of this project was to determine sticking coefficients and reaction probabilities for $\mathrm{CO}, \mathrm{NO}$, and $\mathrm{O}_{2}$ on catalytically relevant surfaces as a function of reactant coverages under conditions resembling those encountered in real catalytic systems. The unique aspect of our research was the fact that we were able to measure sticking coefficients in situations emulating competitive adsorption, either by studying the adsorption of a given gas on a surface partially or totally covered with another type of molecule, or by performing reaction probability experiments with mixtures of two or more gases. For example, carbon monoxide oxidation rates were measured on $\mathrm{Pt}(111)$, either by dosing $\mathrm{CO}$ on pre-oxidized surfaces or by using oxygen/carbon monoxide gas mixtures on clean surfaces. These measurements proved quite useful in providing important kinetic parameters for systems that mimic closely catalytic converters under operational conditions. Realistic sticking coefficients and reaction rates obtained this way may be combined with other reported thermodynamic and kinetic parameters for the relevant surface steps obtained by performing steady state catalytic experiments under high pressures to simulate the kinetics of the overall process (work in progress).

\section{Importance to LANL's Science and Technology Base and National R\&D Needs}

In order to determine the relevant parameters related to the performance of the catalytic converters and to propose changes in catalyst formulations without performing expensive in-situ testing experimentation, it is desirable to study those systems in a laboratory setting. Fortunately, most of the reactions involved in the chemical transformations dealing with the processing of emission gases, namely, $\mathrm{CO}$ oxidation and $\mathrm{NO}_{\mathbf{x}}$ reduction on noble metals such as $\mathrm{Pt}, \mathrm{Pd}$, and $\mathrm{Rh}$, are quite simple, and so the kinetics of each individual step can be determined separately on a relevant model system, and the overall rates for the catalytic conversion processes in automobiles can then be calculated by performing computer 
simulations using those parameters. This approach has already proven quite successful in the past: extensive work has been done on the reactivity of $\mathrm{CO}, \mathrm{NO}$, and $\mathrm{O}_{2}$ on transition metal surfaces which has provided most of the relevant rate constants, and recent calculations have proven that overall rates can indeed be reproduced by using those values.

There is, however, one set of parameters for which there are still no good estimates, namely, those referring to the sticking coefficients for gas molecules impinging on the catalyst surfaces under realistic conditions, namely, when exposed to gas mixtures under atmospheric conditions. This project was a collaborative effort between the University of California, Riverside (UCR) and Los Alamos National Laboratory (LANL) to address this problem.

In terms of the relevance to the LANL mission, competitive adsorption processes also have a key role in a large number of technologically important components of the United States strategic nuclear stockpile. An exact description of how these processes affect the long term storage, safety, and stability of any number of these components is crucial in assisting LANL to meet its strategic goals of safeguarding and dismantling the nation's nuclear stockpile. In this vein we extended the sticking coefficient measurements to other gases and to other relevant oxide surfaces. Furthermore, the ability to effectively couple fundamental physical chemical studies such as those delineated in this project to specific technological problems within the National Laboratory Statement of Mission strengthens the University of California-LANL interface. In the newly emerging role that the national laboratories play in helping American industry meet global economic challenges, the research encompassed by this project very strongly complements several LANL cooperative research and development efforts with General Motors, Ford, and Chrysler. These efforts have involved specific attempts to achieve federally mandated exhaust gas emissions through more active formulations of the materials used in catalytic converters.

\section{Scientific Approach and Accomplishments}

The characterization of competitive adsorption systems was performed by following two parallel approaches, namely, by measuring the dynamics of these processes as a function of gas exposures, and by determining the nature of the adsorbed species through the use of surface sensitive spectroscopic techniques. Dynamic adsorption measurements were performed by using a method originally developed by King and Wells where a collimated 
beam of the gas of interest, generated by using a capillary array, is directed towards the sample while the partial pressure of such gas is recorded using a mass spectrometer [1]. A schematic representation of our ultra-high vacuum set-up is shown in the top portion of Fig. 1. The raw data obtained this way is related directly to both sticking coefficients and absolute coverages through simple equations (Fig. 1, bottom).

As mentioned above, we were interested in determining sticking coefficient values for competitive adsorption situations and reaction probabilities. To that goal we performed experiments such as those delineated below:

1) Dynamic measurement of sticking coefficients and reaction probabilities for surfaces with specific pre-coverages of molecules of interest. In particular, we performed studies for the sticking coefficient of $\mathrm{CO}$ on both clean and oxygen-precovered platinum surfaces [2-4].

2) Measurement of sticking coefficients by using premixed gas mixtures. Measurements were also performed for $\mathrm{CO} / \mathrm{O}_{2}$ gas mixtures of different composition on $\mathrm{Pt}(111)$ using the directional capillary array doser mentioned above [5].

3) Dynamic measurements on the adsorption of one gas in the presence of a preset background pressure of a second gas. Preset background pressures of oxygen were maintained in the chamber while dosing $\mathrm{CO}$ using the collimated beam device.

4) Determination of the kinetics of steady state oxidation reactions at elevated temperatures by performing experiments such as those described in items 2 or 3 above with $\mathrm{CO}$ and oxygen at surface temperatures high enough to favor surface reactions (i.e., $700 \mathrm{~K}$ ) [3, 5]. The steady state evolution of $\mathrm{CO}_{2}$ was followed by using both approaches, by measuring its partial pressure using mass spectrometry or gas chromatography.

These experiments were performed isothermally, and the relevant parameters, namely, the partial pressures, temperatures, and coverages, were varied systematically. As mentioned throughout this report, the initial experiments were conducted on the interactions between $\mathrm{CO}$ and oxygen on $\mathrm{Pt}(111)$ surfaces. Several interesting observations were derived from such investigation. Three temperature regimes were identified for this reaction on surfaces precovered with atomic oxygen (Fig. 2). Below $300 \mathrm{~K}$ no reaction is observed, and the presence of preadsorbed atomic oxygen on the surface does not significantly affect the initial sticking coefficient of $\mathrm{CO}$ but only reduces its saturation coverage by less than half, which it does by preferentially blocking the bridge sites. Above $400 \mathrm{~K}$, on the other hand, 
the desorption of $\mathrm{CO}_{2}$ from oxygen-covered surfaces is controlled by the impinging frequency of the incoming $\mathrm{CO}$. On clean surfaces the oxidation rate is equally determined by the $\mathrm{CO}$ incoming flux as long as the $\mathrm{CO}: \mathrm{O}_{2}$ ratio in the $\mathrm{CO}+\mathrm{O}_{2}$ mixed beams is low. For high $\mathrm{CO}: \mathrm{O}_{2}$ ratios, however, the $\mathrm{CO}$ steady-state coverage increases, poisoning the adsorption of oxygen, and slowing down the overall $\mathrm{CO}_{2}$ production (Fig. 3) [5].

The most interesting temperature range is that between 300 and $400 \mathrm{~K}$, where the rate of surface recombination of $\mathrm{CO}$ with oxygen competes with that of $\mathrm{CO}$ adsorption; under those conditions the overall dynamic behavior is fairly complex, and not all the surface oxygen is reactive [4]. Furthermore, the reaction rates in this regime not only depend on the coverages of the reactants, but also on how the surface is prepared. Two kinetically distinct types of oxygen atoms develop during the course of reaction in spite of the fact that they all sit on identical sites at the start of the kinetic runs, suggesting that the reactivity of chemisorbed $\mathrm{CO}$ depends on the local oxygen coverage of neighboring sites (Fig. 4, left). We propose that such local arrangements modify the adsorption energy for atomic oxygen, and that this in turn changes the activation energy for the oxidation reaction (Fig. 4, right). Previous reported molecular beam experiments were also extended to cover a wider range of surface coverages in order to better determine the dependence of the rate constant for the surface oxidation step on the coverages of $\mathrm{CO}$ and oxygen. It was found that while the presence of oxygen on the surface helps the production of $\mathrm{CO}_{2}$, increasing $\mathrm{CO}$ coverages augments the activation barrier for this reaction (Fig. 5), an observation that is in direct contrast with previous reports [6]. Finally, the adsorption sites for $\mathrm{CO}$ during the surface $\mathrm{CO}+\mathrm{O}$ recombinatory reaction were characterized by reflection-absorption infrared spectroscopy. The data reported here was analyzed and discussed in terms of possible kinetic models [3].

We plan to continue the study of the $\mathrm{CO}+\mathrm{O}_{2}$ reaction by first analyzing the acquired data by comparison with kinetic computer simulations using a Monte Carlo algorithm recently developed in our laboratory at UCR $[7,8]$. This type of study will then be extended to CO-NO, NO-hydrocarbons, and $\mathrm{NO}-\mathrm{O}_{2}$ systems on single crystal surfaces of rhodium, palladium, and platinum-rhodium alloys, as well as on copper-based catalysts. Some preliminary experiments have in fact already been done on the reactivity of NO with propene.

The dynamic experiments discussed above will also be complemented with the spectroscopic characterization of the surface species during the different stages of the 
adsorption process in order to determine relative surface coverages and the degree of lateral spatial aggregation (islanding) of those species. While the coverage of strongly adsorbed species such as oxygen can easily be measured by using either AES or XPS, chemisorbed CO or NO is better characterized by RAIRS: infrared spectroscopy is particularly suited for these experiments because not only are IR signal intensities directly related to surface coverages, but vibrational frequencies are strongly dependent on adsorption sites and on islanding. Single reflection infrared instruments are capable of detecting $\mathrm{CO}$ or NO coverages well below $1 \%$ of a monolayer, and frequency shifts on the order of $1 \mathrm{~cm}^{-1}$. We have just finished a set of RAIRS experiments on the CO-oxygen/Pt(111) system that proves the power of this approach [3].

\section{Publications}

1. Liu, J.; Xu, M.; Nordmeyer, T.; Zaera, F., "Sticking Probabilities for CO Adsorption on Pt(111) Surfaces Revisited", J. Phys. Chem., 99, 6167-6175 (1995).

2. Liu, J.; Xu, M.; Zaera, F.,"Determination of the Rate Limiting Step in the Oxidation of CO on Pt(111) Surfaces", Catal. Lett., 37, 9-13 (1996).

3. Xu, M.; Liu, J.; Zaera, F., "Kinetic Evidence for the Dependence of Surface Reaction Rates on the Distribution of Reactants on the Surface", J. Chem. Phys., 104, 8825-8828 (1996).

4. Zaera, F.; Liu, J.; Xu, M., "Isothermal Study of the Kinetics of Carbon Monoxide Oxidation on Pt(111): Rate Dependence on Surface Coverage", J. Chem. Phys., submitted. 


\section{References}

[1] King, D. A.; Wells, M. G., Surf. Sci., 29, p. 454 (1972).

[2] Liu, J.; Xu, M.; Nordmeyer, T.; Zaera, F., "Sticking Probabilities for CO Adsorption on Pt(111) Surfaces Revisited", J. Phys. Chem., 99, p. 6167 (1995).

[3] Zaera, F.; Liu, J.; Xu, M., "Isothermal Study of the Kinetics of Carbon Monoxide Oxidation on Pt(111): Rate Dependence on Surface Coverages", J. Chem. Phys., submitted (1996).

[4] Xu, M.; Liu, J.; Zaera, F., "Kinetic Evidence for the Dependence of Surface Reaction Rates on the Distribution of Reactants on the Surface", J. Chem. Phys., 104, p. 8825 (1996).

[5] Liu, J.; Xu, M.; Zaera, F., "Determination of the Rate Limiting Step in the Oxidation of CO on Pt(111) Surfaces", Catal. Lett., 37, p. 9 (1996).

[6] Gland, J. L.; Kollin, E. B., "Carbon Monoxide Oxidation on the Pt(111) Surface: Temperature Programmed Reaction of Coadsorbed Atomic Oxygen and Carbon Monoxide", J. Chem. Phys., 78, p. 963 (1983).

[7] Nordmeyer, T.; Zaera, F., "A Monte Carlo Simulation for the Precursor Model of Adsorption of a Spatially Homogeneous Surface", Chem. Phys. Lett., 183, p. 195 (1991).

[8] Nordmeyer, T.; Zaera, F., "A Theoretical Study of the Parameters Affecting the Kinetics of Gas Adsorption on Solid Surfaces", J. Chem. Phys., 97, p. 9345 (1992). 


\section{Sticking Coefficient Measurements \\ King and Wells Set-up}

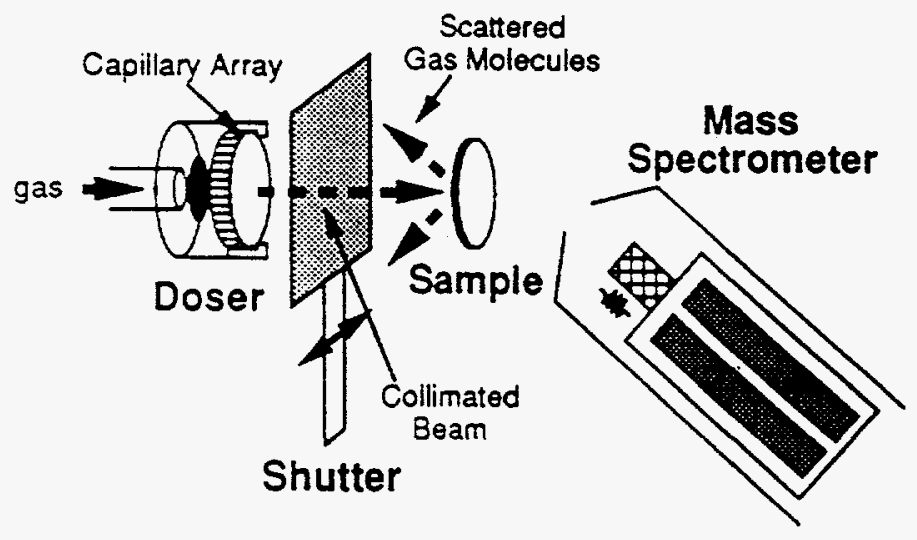

CO Oxidation on $\mathrm{p}(2 \times 2)$ O-Pt(111)

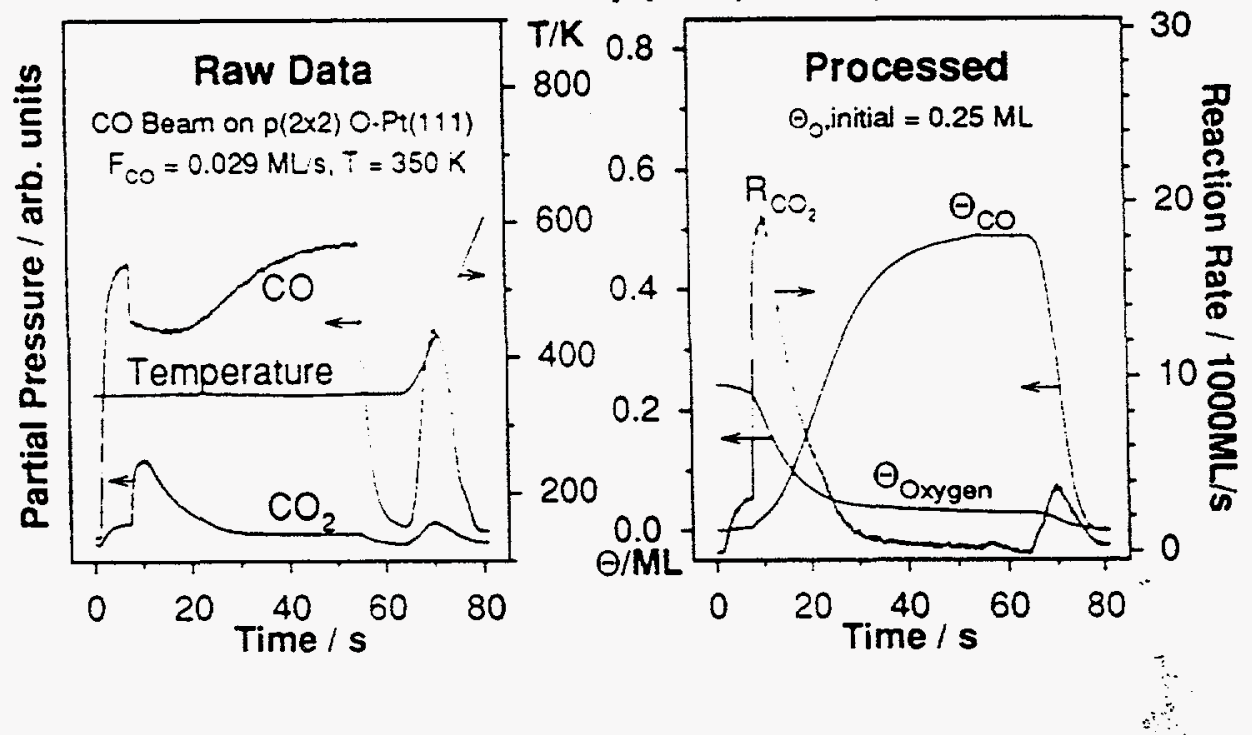

Figure 1. Top: Schematic representation of the experimental set-up used in the dynamic kinetic measurements described in this report. The method is a variation of that originally developed by King and Wells, and consists of a molecular collimated beam doser (generated by using a capillary atray), a shutter, and a mass spectrometer (used for the detection of the gas molecules scattered from the surface). Bottom: Typical data from kinetic measurements obtained by using this experimental set-up. The results displayed here correspond to the oxidation of $\mathrm{CO}$ on an oxygen-presaturated $\mathrm{Pt}(111)$ surface. The left panel shows the raw data, namely, the changes in both carbon monoxide and carbon dioxide partial pressures during the different stages of these experiments, while the right panel displays the temporal evolution of both the coverages of the species involved and the rate of the overall reaction, as calculated from the data shown on the left. In this project we used the methodology illustrated here to measure reaction rates isothermally either at high coverages or under competitive conditions. 


\title{
CO Uptake and $\mathrm{CO}_{2}$ Production on Oxygen Precovered Pt(111) Surfaces
}

\author{
O2 Predose:600 L@ @ $575 \mathrm{~K}$
}
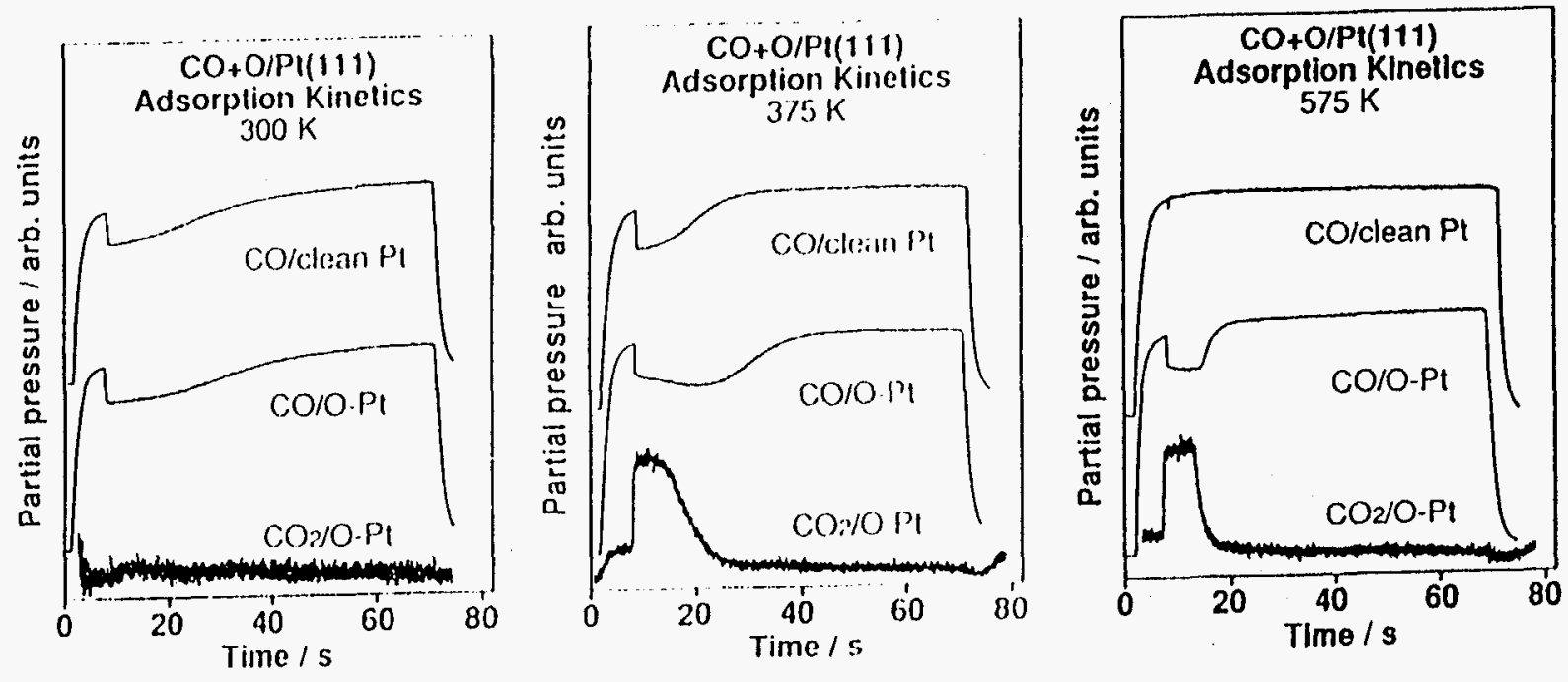

Figure 2. $\mathrm{CO}$ uptake and $\mathrm{CO}_{2}$ production isothermal kinetic measurements on clean and oxygen-precovered $\mathrm{Pt}(111)$ as a function of surface temperature. The three different temperature regimes observed for this reaction are illustrated here by the traces for 300 (left), 375 (center), and 575 (right) $\mathrm{K}$. These data show that the initial sticking probabilities for $\mathrm{CO}$ are not significantly affected by the presence of oxygen atoms on the surface. It is also seen here that at high temperatures, above $400 \mathrm{~K}$, carbon dioxide is produced with high efficiency, at a rate that is controlled by the adsorption of the $\mathrm{CO}$ molecules; the surface recombination between carbon dioxide and oxygen is much faster than the desorption of adsorbed $\mathrm{CO}$. The intermediate temperature range is more complex, and involves the kinetics of the surface $\mathrm{CO}+\mathrm{O}$ recombination step. Data such as these can be used to obtain coverage-dependent reaction rates for each of the relevant step in a catalytic processes under realistic competitive adsorption conditions 


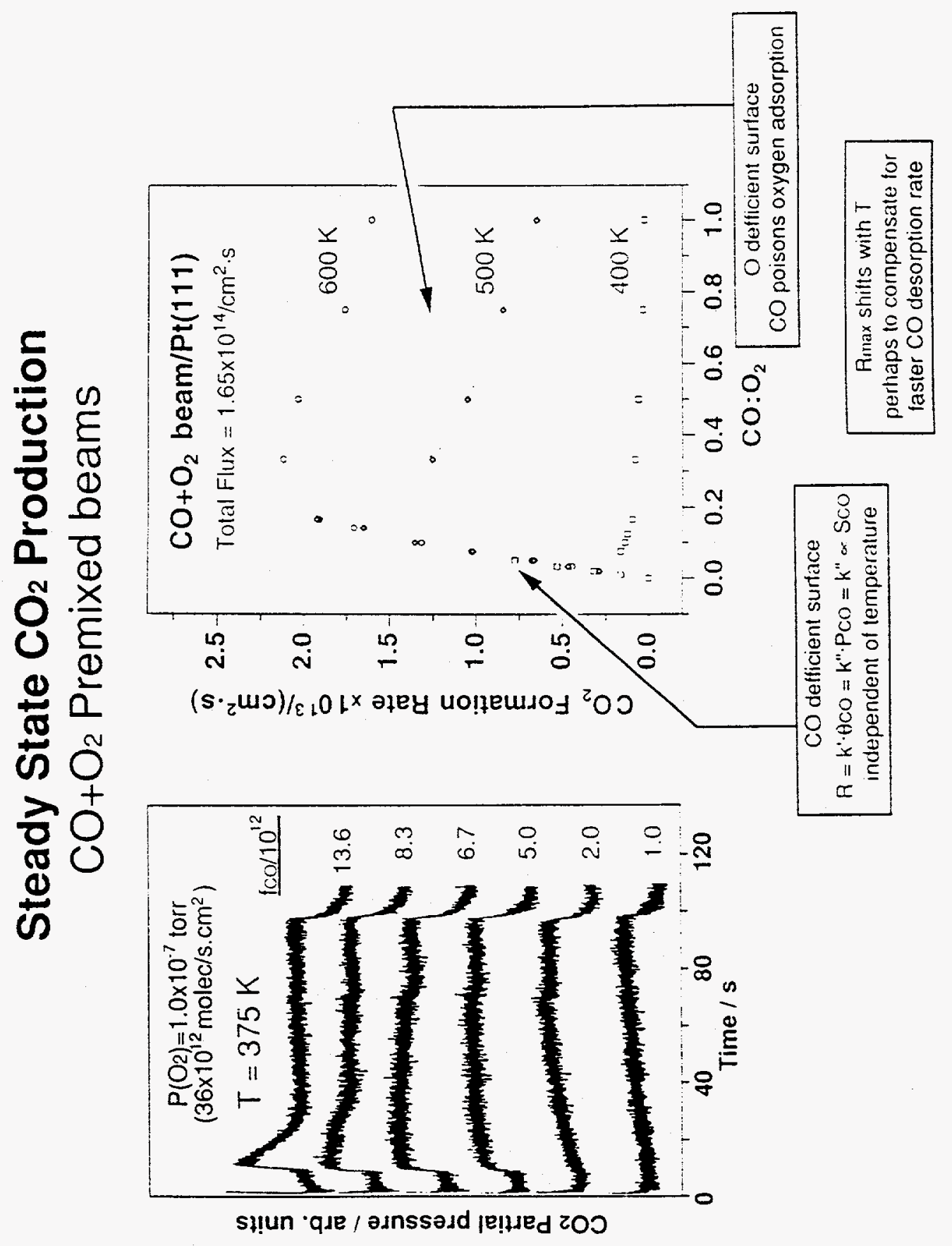




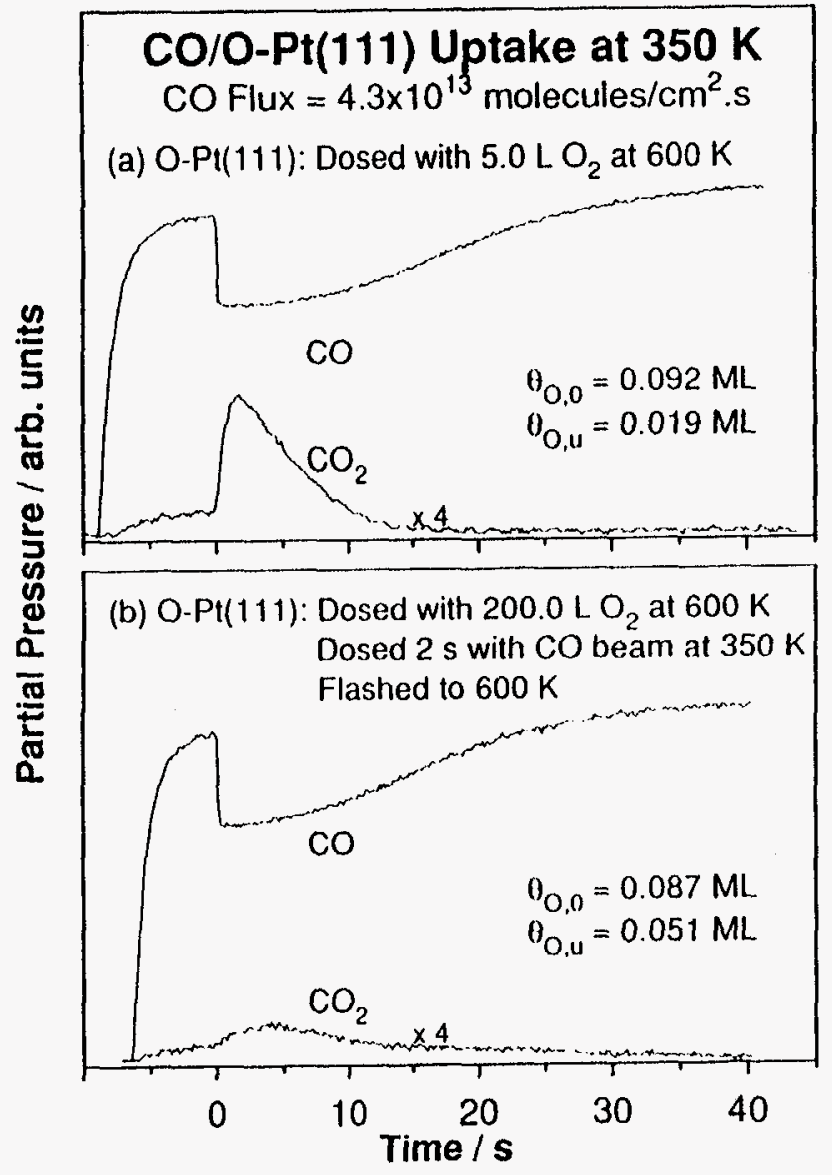

\section{Reaction Models}

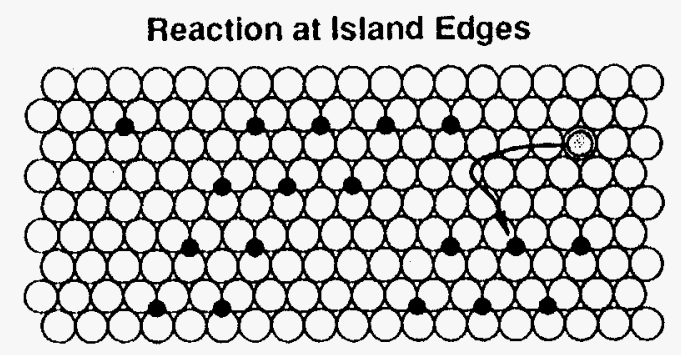

Arguments against it:

1) Rate.. (k), not fractional order

2) $\mathrm{So}(\mathrm{CO})$ is high from the very beginning

3) Does not explain unreactive oxygen

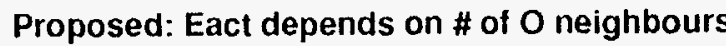

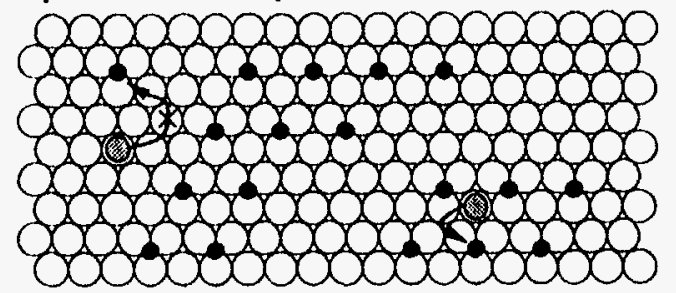

- O atoms $\quad \mathrm{OCO}$

Figure 4. Left: $\mathrm{CO}$ uptake and $\mathrm{CO}_{2}$ time evolution data for $\mathrm{CO}$ oxidation reactions on two differently-prepared oxygen-covered $\mathrm{Pt}(111)$ surfaces at 350 $\mathrm{K}$. The initial oxygen and $\mathrm{CO}$ coverages were about the same in both cases, but the kinetic behavior was still different because of the difference in spatial distribution of the oxygen atoms within the surface. Right: Models proposed to explain the Iwo types of oxygen seen in the kinetic studies for $\mathrm{CO}$ oxidation on $\mathrm{Pt}(111)$ between 300 and $400 \mathrm{~K}$. The top scheme summarizes the old idea that proposes that $\mathrm{CO}$ can only react at the perimeter of oxygen islands. The bottom diagram depicts our alternative hypothesis, where it is suggested that the weaker $\mathrm{CO}$ adsorption in the middle of oxygen islands makes the $\mathrm{CO}+\mathrm{O}$ reaction go faster there. 


\section{CO Oxidation on $\mathrm{p}(2 \times 2)$ O-Pt(111)}
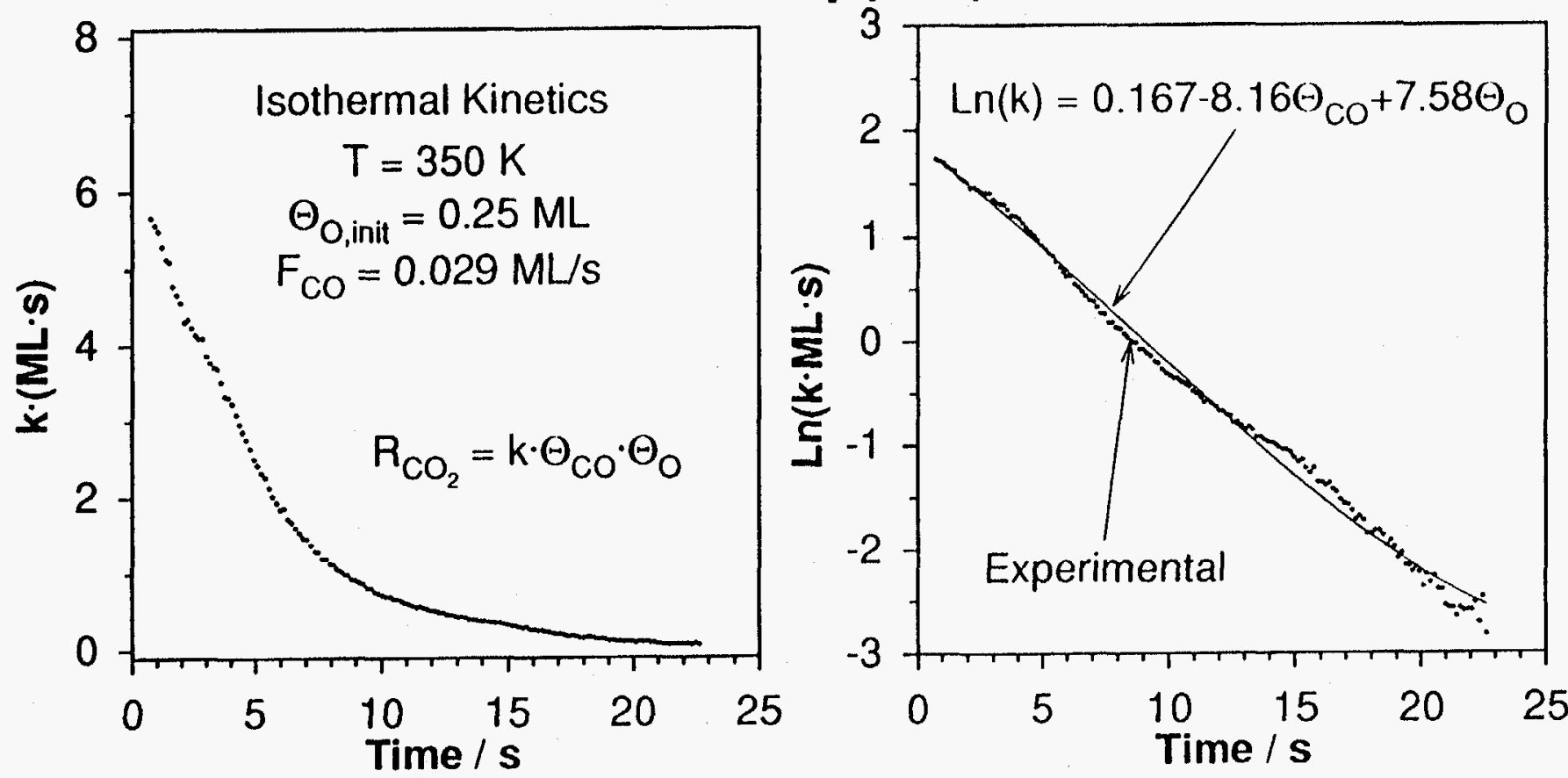

Figure 5. Analysis of kinetic data such as those shown in Fig. 1 indicates that the surface recombination step between adsorbed carbon monoxide and oxygen follows a second order rate law (first order in each of the reactants), and is therefore most likely an elementary step. A closer look at the behavior of the reaction constant $k$, however, indicates that the rate expression is more complex than that of a normal gas-phase step. The left frame shows the temporal evolution of $k$ for the data provided in Fig. 1, while the right frame displays a fit of that curve to an exponential expression. These calculations highlight the fact that the activation energy for the surface reaction depends strongly on the coverages of the reactants. This type of analysis provides some insight on the microscopic detail of the kinetic of surface reactions. 